\title{
"Can the UN WTO and the Colombian government policies promoting ecotourism, contribute to rural territorial development"
}

\author{
H. Rojas-Pinilla \\ Rural and Regional Development Department, \\ Environmental and Rural Studies Faculty, \\ Pontificia Universidad Javeriana Bogotá, Colombia
}

\begin{abstract}
The UN WTO and national governments worldwide have been promoting Sustainable Tourism (ST) as a promising activity for alternative development, particularly for the Sustainable Development of rural areas. However, the Territorial Rural Development (TRD) perspective is focused on analyzing Power relations, namely how different stakeholders at various levels (local, national and international) have different possibilities of practicing power in terms of access, control and distribution of tourism resources in six main dimensions; social, economic, ecological, institutional, political and cultural. The aim of this paper is to analyze the UN WTO and the Colombian Government policies to promote ecotourism, and their possibility to effectively contribute from the power approach to TRD.

Keywords: sustainable tourism, tourism resources, alternative development, territorial rural development, power relations, public policy.
\end{abstract}

\section{Introduction}

The present article is the result of a research project funded totally by the Pontificia Universidad Javeriana Research Office in Bogotá, Colombia. 


\section{Territorial rural development}

Rural livelihoods have changed a great deal in the last decades, particularly in their traditional functions of production and reproduction. Most rural households show a large increase in non-rural income ratio compared to agricultural income [1]. In emerging rural studies, for instance, the approach defined as Nueva Ruralidad (New Rurality) has acknowledged the rapid increase of new non-farm activities and their increasing importance for rural household income. Therefore service activities such as tourism and related services (crafts, small manufacturing, transportation, communications, commerce, personal services, etc) have been perceived as potential income generating activities for households, and promising alternatives for rural development and poverty alleviation [2].

Territorial Rural Development has been defined by scholars as "the process of institutional and productive transformation in a determined rural space whose aim is to reduce rural poverty" Schejtman and Berdegue [3]. However, this definition left other dimensions of territory behind (environmental, cultural and political); more importantly, how relations of power in terms of access, control and distribution of resources are established between different stakeholders within a territory at different levels (local, national, regional, and global). This will be explained in detail. Territory cannot been seen simply as a physical space in which a community is located, it is also an imaginary space and "the scenario produced by a social construction that allows the development of cultural, economic, politic and social relations, implies a sense of belonging, identity and territoriality is hence a historic concept" [4]. However, this view has some limitations when it focuses on productive development and institutional change leaving out the cultural, social and political life, particularly the basic and fundamental meaning of territory, when is conceived from the power relations perspective. Schneider and Peyre [5] review the evolution of the concept extensively, and correlate territory and power exercise over an area, namely people, activities and resources; consequently, there are many dimensions in which it is possible to exercise power in terms of access, control and distribution of people, activities and the allocation of resources in order to accomplish any economic activity.

For example a municipality may have control over seashore possible uses. But it may not have real control over the access to it, for example it cannot control the boats, or terrestrial transportation which may be in the hands of local people or in hands of a national travel agency. From the cultural dimension, the imaginarium of a given fisher community e and its myths may be of a restricted access for a particular group of the community that control it (religious leaders) or might be something that might be appropriate for an outsider and popularized, to be sold and commercialized, in a form of souvenir craft, image, etc. A national government might give rights and permission to a national or international tourist enterprise for using a common resource as the beach as a touristic resource over regional actors, therefore diminishing local people rights to access, distribute, or control it. As a result, from a territorial analysis perspective, it is essential to 
assess power relations between actors at different scales and their asymmetries in terms of control, access and distribution of resources in the territory in each of the main dimensions (economic, social, political, etc., See figure 1). One useful instrument may be the stakeholder analysis, combining stakeholders, the dimension in which are possible exercise power relations and the cumulative effects of those relations on sustainability.

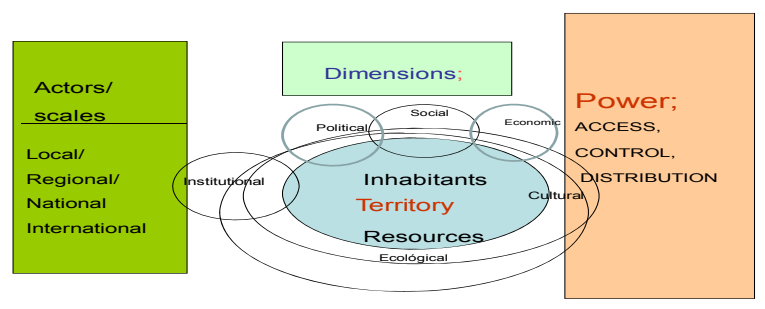

Figure 1: Territorial analysis.

In the economic dimension from the territorial perspective, it is necessary to identify and analyze how access, control and distribution of economic resources derived from touristic activities are divided between local, regional, national and international actors. According to Schulte [6] large transnational companies such as airline and hotel services, benefit the most from tourism earnings over the local and regional populations. It is also possible to identify the quantity and quality of the jobs generated by tourist enterprises, in terms of, for example, stability, income, or self satisfaction.

It is also possible, to identify and analyze the quality and quantity of productive opportunities generated by tourism, or real access to services and resources such as public spaces, drinking water, and even the tourist attractions placed within their territories (beaches, forests, archaeological or heritage sites, etc) in a broader way.

Within the environmental dimension not only the type of impacts which arise from the activity as a whole must be identified (derived from for instance the provision of food services, lodging and transportation, in addition to other services such as laundry etc.) but also the impacts of each particular activity performed by tourists (horseback riding, canoeing, etc.) as well as their cumulative effects [7] including how each of these impacts affect different social groups, by gender, age ranges and socioeconomic status. For instance, how the offer of food in high seasons is reduced for them, or prices for all for or for a particular type of food (i. e. seafood) are increased. How certain tourist activities reduce the productivity of particular ecosystems on which people depend i.e. fish resources for local fishermen or polluted the water they depend on for drinking (i.e. trekking in the highlands). Whereas, within the cultural dimension, aspects of analysis are even more complex, since they require longer time scenarios to 
demonstrate changes in, culture, imagery, symbolism not to mention on the effects on lifestyles and local community consumption patterns. Within the political dimension it is necessary to establish the way in which decisions are taken, depending on the interests of local and regional actors versus outsiders, but especially in the light of the collective interest and collective well-being at local, regional and national level. Finally, as regards the institutional dimension one can, for example, research and analyse to what extent the institutional apparatus is responsive to the needs and interests of the different stakeholders involved in the activity at all levels. Also how local institutions and actors perform a particular role, for instance, as guarantors and compliance of environmental and labour standard regulations, while maintaining favourable conditions for the flourishing of the activity under parameters that not only privilege economic growth and revenue generation but common welfare, transparency, good governance and accountability in terms of the law among others.

\section{Sustainable development and sustainable tourism in UN WTO: the concepts and declarations in the last ten years}

In the past, productive processes that encompass development and economic growth only report as costs those included in the regular accounting process. Throughout the $19^{\text {th }}$ and $20^{\text {th }}$ centuries the world has accumulated the heavy environmental costs of human production and reproduction. Climate Change, for instance, forces us today to confront a number of challenges in order to transform our way of production, consumption and live in a more sustainable manner, as well as the realization of how dependant we still are on nature in spite of our technological advancement.

\subsection{The concept of sustainability in UN WTO declarations}

WTO [8] outlined the general principles of Sustainable Tourism (TS) defined as "that ..(tourism) directed to the management of all resources in a way that economic, social and aesthetic needs can be sustained while maintaining cultural integrity, essential biological processes, ecological processes and the biodiversity systems that support life on the planet". From the perspective of Meadows et al [9] and the Second Law of Thermodynamics, this definition presents strong and obvious contradictions because it is not possible to meet the growing economic demands, the social and aesthetic needs of continued population growth while, at the same time, ensuring cultural integrity, the maintenance of essential biological processes, global ecological processes and the biodiversity systems that support life on the planet. Some of the most controversial topics linked to this definition of sustainable development are; whose necessities and needs, ought to be fulfilled and for whom. Other questions include: what is sustainability? How do we understand sustainability in a comprehensive way? The first question brings the notion of equity into discussion not only at a trans generational level, which implies future generations, but also at intergenerational one. An adequate notion 
of equity referred to sustainable development implies two directions in the satisfaction of needs, those of both the present and the future generations Hunter [10] quoting Fox, about the subject of intergenerational and intergenerational equity established that "issues have become interwoven in a complex debate on how best to achieve equity of access to natural resources which create human well-being, and in the distribution of the costs and benefits (social, economic, and environmental) which ensue from the utilization of resources". In consequence, any development that "maintains, creates, or widens spatial or temporal differences in human well being" is simply not sustainable.

Secondly, as a consequence of criticism over the concept of sustainability was revised and the notion of resilience was introduced, referred to the capacity of nature for self-restoration and conversely continuing performing its natural functions and evolving processes. Hence the notion of sustainability included a new and more applicable meaning in practice; guaranteeing or, at least, procuring that interventions directed to development do not affect the natural capacity of ecosystems for self restoration, some ecologists still argued that maintaining the natural capacity of ecosystems for regeneration was not enough and they proposed that the notion of sustainability should incorporate at least the maintenance of a team of basic functions such as; habitat, regulation, production and information R.S. de Groot et al. [11].

In the particular case of ST definitions, McMinn [12] quotes several authors that disqualify the concept, and even consider it as another cliché of the development discourse (Muller); while some authors wonder about how it would be achieved (O'Gready, Pleumarom, Carter, and Wheat ), others search for its real meaning (Cronin, Wall), while the most critical thinkers argued that in certain occasions what is proposed as ST "can be even worse in the long term that conventional tourism" (Buttler). The revised notion of sustainability still avoids confronting the social, economic and political context in which development processes take place. Hunter [10] in the document Sustainable Tourism an Adaptative Paradigm, points out several key issues in defining sustainability from engineering, economy, the political economy, and other disciplinary perspectives. Such, as the functions of economic growth in welfare provision; the impacts and importance of population growth; the forgotten fact that growth Encompasses limits; the actual difficulties in the substitution of natural capital by capital manufactured by men; the real capacity of our society to substitute non renewable resources for renewable ones; the current real technological capacity to avoid negative environmental impacts; ethics, and the rights of non human species to survive, among many other controversial issues that are still unresolved.

In Rio the coining of 'ecotourism' was not casual; it was part of the conservationism bias at the conference, and was ideated as a relatively safe way to obtain financial resources for conservation of biodiversity, one of the main impediments for biodiversity conservation in the South. However, the notion of ecotourism tends to be often confused with ST, but ecotourism has been seen as a part of specialized tourist activities under the umbrella of ST. In 1995 at the Lanzarote Conference, social, cultural and economic variables were linked, as 
part of the sustainability of tourism activities. Particularly on issues such as broad participation across all scales, the need to improve the quality of life of host communities, respect for traditions of local communities, codes of conduct, in addition to concerns about transport, energy use and nonrenewable resources, as well as recycling and waste management produced by the activity [14].

At the Quebec Conference [16], it was clearly established that ecotourism holds the principles of ST in relation with the avoidance of social, economical and environmental negative impacts of tourism but also it was specified that ecotourism contributes actively to natural and cultural heritage conservation; includes local and native communities in their planning and development and their welfare, it works better on independent travelers as well as to reduce crowds. Some authors considered that ecotourism emerged as a fragmented vision of sustainable development, because it assumes that there are particular areas and spaces in which is important to implement sustainable practices, and others in which it is not necessary. Furthermore, Branwell and Lane [13] believe that ST and categories such as ecotourism should not be seen as a segmen of the tourism sector, its relevance resides in the transversality of its activities and the different sectors and disciplines that encompass. ST is a key in the application of ideas in sustainable development and it is a potential tool for develop it. In other words all tourist activities should been sustainable in every possible dimension, and if we can achieve that it would not be necessary to reserve spaces for conservation, in this context conservation would be a reality and not an objective.

In August 2004 [8] the UN WTO reformulated the concept of ST including a group of sustainability principles intended to avoid the environmental, economic and socio-cultural issues related to tourism development and, therefore, establishing an adequate balance between these three dimensions to guarantee its sustainability in the long run. The UN Environmental Commission recommended a set of principles for ST initiatives development, such us the optimum use of environmental resources as a key factor in tourism development, the maintenance of essential ecological processes which contribute to conserve

Biodiversity and cultural heritage; respect for socio-cultural community authenticity, traditional values and the contribution to tolerance and intercultural understanding; ensure viable economic operations in the long run providing socioeconomic benefits fairly distributed between stakeholders, including employment stability, income generation opportunities, community social services and poverty alleviation.

\subsection{The declarations brief analysis}

In the Berlin Declaration [15], the concept of sustainability utilized is still in line with that used at the Rio Declaration, and the main theme of the Conference is the relationship between biological diversity and tourism. The document incorporates environmental and social elements in its emphasis; the most important concern is about the distribution among the population and local economies of benefits from sustainable use of biodiversity. 
The document proposes a team of tools and mechanisms to ensure the objective accomplishment, but without actually targeting the objective of redistribute the benefits of biodiversity used in tourist activities. Roughly the mechanisms proposed are: i) economical incentives through bilateral and multilateral funding, ii) Command and control and the use of sanctions for infractions.iii) planning and management of tourist activities; iv) the implementation of the Action Plans in Biodiversity in which all participating countries pledged at Rio, as well as the monitoring of impacts on biota (water, soil, air, land and biodiversity, especially through an integrated management of coastal and marine). It also expresses special concern about the adoption of clean technologies and. v) training, proposing an increase of tourism professionals in biodiversity issues, and insists on vi) broad participation of all actors at all levels. The Berlin Declaration has a strong bias toward conservation and ecotourism. TS is still perceived as a major economic activity with strong potential in generating financial resources for conservation.

In the declaration the need for conversion of existing systems arise as well as the necessary implementation of restrictions on use. On the positive side, while proposing the implementation of mechanisms for sharing benefits of biodiversity, it fails to acknowledge the power asymmetries between regional, local and national stakeholders in terms of access to control or the distribution of technology, capital, and markets; furthermore it does not recognize the power differences between North and South or Transnational Hotels and transportation enterprises. In practice, traditional communities (ethnic, rural, etc.) are often not capable of taking advantage of the opportunities offered by tourism activities, having instead to cope with a number of "negative externalities" such as the limited access to common use resources, (i.e. forest, rivers and sea) as well as the deterioration of the productive capacity of these resources on which they have historically depended for natural and cultural survival . The progressive increase in pollution and environmental impacts (noise, pollution, water, visual pollution, solid waste, etc.) increased taxes, cost of living, labor and the gradual Displacement of traditional activities generate processes of social differentiation or job insecurity.

On the other hand, without information systems articulated to an efficient monitoring system is almost impossible to make decisions directed towards conservation, sustainable use or equitable distribution of benefits. In countries like Colombia, highly diverse but with weak institutions, as well as social and economic exclusionary structures, the final result is unequivocally determined by the initial conditions. Conversely, it seems quite difficult to contribute to the complex process of transforming the power relations in different dimensions and scales incorporated in tourism activities without changing power relations, or enhancing or making the access, control or distribution between local stakeholders more equitable.

The Quebec Declaration's, [16] main subject, as mentioned before, is Ecotourism, it reiterates that ecotourism is a way to get resources for the conservation and management of protected areas rich in biodiversity and culture and its preservation for future generations. In the declaration promote the 
creation of Small and Medium Enterprises (SMEs) are proposed - access to credit, markets, subsidies, including incentives for renewable energy and technical solutions. It incorporates cultural and political considerations as well as respect for human rights in relation to land and property and, where recognized, the right to self determination and cultural sovereignty of indigenous and local communities, including their protected, sensitive or sacred sites, and their traditional know-how for which they operational tools are proposed. While acknowledging the poverty of the host communities in tourism destinations, it states that different forms of tourism, especially ecotourism, "if managed sustainably, can represent a valuable economic opportunity for local and indigenous populations their cultures as well as for conservation". Prioritize the planning, development and management of ecotourism and the participation to prevent "the deterioration of the natural landscape, endangering wildlife and biodiversity, coastal and marine pollution, the depletion of water quality, poverty, the displacement of indigenous and local communities and the erosion of cultural traditions" [16]. The document seems to ignore the requirements of multilateral financial institutions like the IMF or World Bank, the suspension of protectionist measures or state incentives. It makes no reference to the asymmetries in access, control and distribution of tourism resources in recipient countries and between national and local communities.

The Galapagos Declaration [17], considers tourism as a global social, cultural and economic phenomenon, and one of the fastest growing activities contributing to economic and social development of peoples and proclaimed it as a sounded strategy to combat poverty" [17] Like the Berlin Declaration, it proposes an updated version of the same instruments, adheres to the Convention on Biological Diversity United Nations, "in order to sustain and distribute fairly and equitably the benefits arising from their use" [17]. It proposes tools intended to achieve their goals and recommendations and believes diffusion and communication are the best way to put in action its recommendations. Like previous statements, it does not take into account the asymmetric power between stakeholders in terms of control, access and distribution of tourism resources, knowledge and research capacity, and cannot even commit participating countries to formulate development plans on ST.

The Johannesburg Declaration [18] focuses on Inequality and its effects on the sustainability of development. It proposes to defend workers' rights, dialogue and cooperation. In this respect, it refers clearly to the asymmetries of power, access, control and use of natural resources, biodiversity and tourism between the actors involved. Despite being fairly comprehensive and integrated, the Declaration does not stress rural development as a tool to integrate the objective of combating poverty, as defined in policy development with the environmental objectives of the post-Rio process. It aims to look at the participating countries giving priority attention to structural problems such as hunger, malnutrition, occupation, armed conflicts, illegal trafficking, organized crime, corruption, natural disasters, terrorism, intolerance and incitement to racial, ethnic, religious and otherwise, xenophobia and endemic, communicable and chronic diseases. Also, it points out the intra-generational inequities issues, and the effects and 
relationships between inequity and the implementation of unsustainable patterns of natural resource use, global capital flows, information and the uneven distribution of benefits and costs of globalization.

The Davos Declaration [19] establishes that "the tourism sector must rapidly respond to climate change in the framework that the United Nations is creating so it can grow in a sustainable manner" (UN, Davos, 2007:1), the statement proposes the promotion of instruments to access new technologies to improve effectiveness of using energy and seeking ways to mitigate emissions of greenhouse gases, mainly because of tourist industry transportation and accommodation activities generate an important footprint on the environment.

The Colombian Policy [20] for the development of ecotourism utilizes an odd mixture of Brundtalnd's definition and Sustainable Human Development. It proposes nine strategic lines, in line with most of the UN declarations already reviewed. The policy is conceived of as an instrument for increasing ecotourist activities mainly from an economic perspective than from an ecological or social one. The focus of poverty and sustainable use of biodiversity is absent, as well as the issue of the distribution of costs and benefits or power asymmetries between the actors involved. The mechanism that has been rapidly put in to practice is concession of ecotourism services to private enterprises arguing that tourist activity management demands excessive human and capital resources from the national authority in charge of managing protected areas; the Special Administrative Office of Protected Natural Areas (UASPNN).

Nevertheless figures collected by Goméz [21] show that income derived from entrance charges in the natural parks have declined dramatically as the price of services charged by private companies are $300 \%$ more expensive than previous government prices and furthermore the body finances of the UASPNN have not improved with the income received from these concessions.

\section{Conclusions}

The concept of sustainability in tourism promoted by the UN WTO has been enriched in recent years, gradually identifying the close relationship between equity in access to and use of resources and the sustainable use and management of biological and cultural diversity. Ever since the Conference of Lanzarote, the $\mathrm{UN}$ has insisted on the need to make regular use and codes of conduct in national policies and mechanisms for a broad participation of communities at all levels in tourism activities and, therefore, improving the economic quality of life of host communities as well as ensuring respect for cultural traditions.

It could be said that to some degree it has been an advance in the environmental dimension, but in the economic and political dimensions there are still many challenges, particularly in a South country context with rampant social exclusion, poverty and low skills of most of the rural population. This structural context makes not only political participation but economic and social development in tourism activities difficult, even in communities with a long history of providing services in the vicinity of important protected areas. Pilar Gómez [21] in her research on the participation of tourist services providers in 
the Los Nevados national park found that participation, in spite of the Colombian policy on ecotourism, is quite precarious.

While the process of granting tourist services in national parks was inspired by the Rio principles, and on the paper under the assumptions of the UN WTO conferences, in practice it excludes "fairness and reduces opportunities for the participation of local people. "Moreover the exclusion of local people has generated negative effects on the social level in terms of membership and environmental protection in the park, the community is becoming careless of responsibility in conservation, because they do not perceive the natural area as a resource of their own, as prior to the concession process." "Local actors were not involved in the planning and management of tourism activities, the benefits they receive are minimal, and they do not share their needs and interests".

While changes in the approaches proposed by the UN in its conference for sustainable tourism have much to contribute to the DRT, the fundamental weakness underlie in the impossibility of implementing its principles through operative instruments that reach all levels and dimensions, considering the territorial imbalances of power that are present in all developing countries, there are few cases in which tourism contributes to the DRT and the designated functions in terms of generating more equitable conditions. From the perspective of access, control and distribution of resources local actors are rarely able to benefit from the opportunities generated by tourism and more likely to suffer negative externalities such as increased cost of living, rising cost of real estate growth, taxes, and insecurity. The only way we can achieve sustainable tourism is in a society that has achieved some degree of sustainable development in an integral and comprehensive manner. In the case of the Declarations examined, they have made significant contributions in terms of engaging topics as codes of conduct and social responsibility that aim to help the fight against poverty and exclusion and promote the sustainable use of biodiversity and its connection with cultural diversity. However, the executing governmental agencies of the Colombian policy in charge of the promotion of ecotourism have no operative instruments to contribute to poverty alleviation, culture and sustainable use that the UN WTO declarations promote.

The proposed principles seem not to go beyond an inventory of good intentions, aimed at formulating policy objectives and strategies without a civil and institutional capacity to implement efficient policy instruments (planning, command and control, regulations or incentives), nor have resulted in the implementation of effective monitoring and evaluation systems in order to play a key role in decision making and feedback in the protected natural areas objectives achievement.

According to Gomez [21] In the case of Los Nevados Natural Park, the concession of tourist services to private enterprises has reduced the opportunities for income generation of the inhabitants of the buffer zone in the park by importing food " of high quality and certified " for the tourists, that before was purchased from local producers. In conclusion we can say that on the one hand, with the conceptual advance on the issue of sustainability of tourism, it has become more and more integrated in terms of incorporating a larger number of 
dimensions and considerations, while on the other, it has placed additional complexities, challenges on the process of establishing operational criteria for the planning and implementation to achieve development from the RTD perspective.

\section{References}

[1] Martínez Valle, Luciano. El campesino andino y la globalización a finales de siglo (una mirada sobre el caso ecuatoriano), en, Revista Europea de Estudios Latinoamericanos y del Caribe, No 77, Ámsterdam. pp. 27-35, 2004

[2] Perez, E. \& Farah, M A. Compiladoras. Desarrollo Rural y Nueva Ruralidad en América Latina y la Unión Europea. PUJ, Bogotá, 2004

[3] Schetjtman, A. \& Berdegue, J. Desarrollo Territorial Rural: Aspectos destacados de experiencias en proceso en América Latina y el Caribe. Fondo Internacional de Desarrollo Agrícola y el Departamento de Desarrollo Sustentable del Banco Interamericano de Desarrollo. Santiago de Chile: RIMISP. 2003.

[4] Coy, Uriel. Sistemas Territoriales y Ordenación del Territorio, en Revista Misión Local, Universidad Distrital Francisco José de Caldas. pp. 13-17 4(2) Abril de 1998.

[5] Schneider, S \& Peyre I. Territorio y Enfoque Territorial: de las referencias cognitivas a los aportes aplicados al análisis de los procesos sociales rurales, en, Desarrollo Rural, Organizaciones, Instituciones y Territorios. Manzanal et al, Compiladores. Ediciones CICCUS. 2006, pp. 71-101.2006.

[6] Schulte, S. Guía conceptual y metodológica para el desarrollo y la planificación del sector Turismo. ILPES, CEPAL, Santiago de Chile, Julio 2003.

[7] Rojas-Pinilla, H El Turismo Rural, ¿Alternativa de Desarrollo?, en, La Enseñanza del Desarrollo Rural, Enfoques y Perspectivas. Memorias Seminario Internacional Enfoques y perspectivas de la enseñanza del Desarrollo Rural. pp. 321-343.Del 31 de agosto al 2 de septiembre de 2005 Bogotá.

[8] Conceptos y definiciones; desarrollo sostenible del turismo. WTO. Online $\mathrm{http}: / / w w w . w o r l d-t o u r i s m . o r g /$ sustainable/esp/top/concepts.html.

[9] Meadows, D. et al., Limits to Growth: A Report for the Club of Rome's Project on the Predicament of Mankind, New American Library, 1977, paperback, Universe Books.1972.

[10] Hunter, Collin. Sustainable Tourism as an adaptative paradigm.En Annals of Tourism Research, Vol. 24, No. 4, pp. 850-867.850-867.1997.

[11] Rudolf S. de Groot et al. The Dynamics and Value of Ecosystem Services: Integrating Economic and Ecological Perspectives A typology for the classification, description and valuation of ecosystem functions, goods and services Ecological Economics 41.pp. 393-408 2002

[12] McMinn, S., The Challenge of Sustainable Tourism. The Environmentalist 17, pp. 135-141. Chapman \& Hall.1997. 
[13] Branwell, B \& Lane Bernard. From Niche to General Relevance? Sustainable Tourism, Research and the Role of Tourist Journals, in The Journal of Tourism Studies Vol 16. No 2,pp 52-62.2005

[14] ONU. Carta de Turismo de Lanzarote.1995.

[15] ONU (PNUMA) (1997) Declaración de Berlín. http://www.scribd.com/doc /6376285/Declaracion-de-Berlin

[16] ONU Declaración de Quebec sobre el Ecoturismo (2002). http://www.cinu.org.mx/eventos/turismo2002/doctos/dec_quebec.htm

[17] ONU Declaración de Galápagos (2002) http://www.cinu.org.mx /eventos/turismo2002/doctos/dec_gala.htm

[18] ONU Declaración de Johannesburgo (2003) http://www.un.org/esa /sustdev/documents/WSSD_POI_PD/Spanish/WSSDsp_PD.htm

[19] ONU Declaración de Davos (2007) http://www.centroamerica.tv/es /cambio_clim\%C3\%A1tico_y_turismo_-_responder_los_retos_mundiales

[20] Ministerio del Medio Ambiente Vivienda y Desarrollo Territorial Colombia (MMAVDT) Política Colombiana de Fomento al Ecoturismo (2003).

[21] Gómez, Pilar. La Participación de los prestadores de servicios turísticos y sus consecuencias en la sostenibilidad Ambiental y Social del PNN Los Nevados.\{trabajo de grado\}, Bogotá. Pontificia Universidad Javeriana. Carrera de Ecología. 2008. 